\title{
Causes, Management And Outcome DF Stridor In Infants-A Prospective Study In Tertiary Care Hospital In Kanyakurai District
}

\author{
Dr. Adhavan.E ${ }^{*}$, Dr.Kiren.T ${ }^{* * *}$, Dr.Gopakumar K.P ${ }^{* * *}$ Dr.Chethan Kumar.G ${ }^{* * * *}$ \\ * Junior Resident Department of Otorhinolaryngology, SreeMookambika Institute of Medical Sciences, \\ Kulasekharam, Tamilnadu \\ ** Assistant Professor Department of Otorhinolaryngology, SreeMookambika Institute of Medical Sciences, \\ Kulasekharam, Tamilnadu \\ ,*** Professor and Head of the Department of Otorhinolaryngology, SreeMookambika Institute of Medical Sciences, Kulasekharam, \\ Tamilnadu \\ ${ }^{* * * * *}$ Associate Professor Department of Otorhinolaryngology, SreeMookambika Institute of Medical Sciences, \\ Kulasekharam, Tamilnadu
}

DOI: 10.29322/IJSRP.10.03.2020.p9907

http://dx.doi.org/10.29322/IJSRP.10.03.2020.p9907

\begin{abstract}
Introduction: Stridor may be congenital or acquired. It can be acute, intermittent or chronic. Laryngotracheal inflammation (croup) is the most common cause of acute stridor. Laryngomalacia is the most common cause of chronic stridor. In the infant and newborn, stridor usually indicates a congenital disorder including laryngomalacia, vocal cord paralysis or subglottic stenosis ${ }^{1}$. Most of the studies related to causes, management and outcome of stridor are from western countries. From India there are only limited studies. So, we did this study of stridor in infants and newborns in a tertiary care centre. Here we get the privilege to treat a lot of children with breathing difficulty and noisy respiration ${ }^{\wedge}$ who are referred from peripheral hospitals because of unavailability of resources and equipment.

So, we did this study to describe the common causes, management and short term outcome of stridor in infants and neonates in an Indian scenario.
\end{abstract}

AIM:

To study the causes of stridor in infants and describe the management and follow short term outcome of stridor in infants in a tertiary care centre.

\section{MATERIALS AND METHODS}

\section{STUDY DESIGN:}

A prospective descriptive study

\subsection{SAMPLE SIZE}

Sample size was calculated using the equation:

$$
\mathrm{n}=\mathrm{z}^{2} \times \mathrm{p} \times(100-\mathrm{p})
$$

where, $\mathrm{a}=$ Type I error $« 5 \%$

$\mathrm{z}_{\mathrm{a}}=1.96$

$\mathrm{p}=$ expected proportion of variable of interest

$\%$ of infants with laryngomalacia $=60 \%$, obtained from the study - Laryngomalacia:

disease presentation, spectrum, and management by Landry AM et al.

$\mathrm{p}=60 \% \mathrm{~d}=$ allowable error $\ll 10-20 \%$ of $\mathrm{p}=(20 / 1-00) \times 60=12 \mathrm{~d}=12$

$(1.96)^{2} \mathrm{X} 60 \mathrm{X} 40$

Thus, $\mathrm{n}=\quad-\quad=64$ 
The sample size, $\mathrm{n}=64$

\section{Conclusions:}

The following conclusions were made from this prospective descriptive study:

\section{Primary outcome - Common causes of stridor in infants}

1. Congenital causes were more common than acquired causes.

2. Laryngomalcia was the most common cause of stridor $(68.8 \%)$ in infants presented our centre. Type I was the most common subtype followed by type II, followed by type III and combination of types I and II.

3. The second common cause was bilateral vocal cord motion impairment $(12.5 \%)$.

4. The third common cause was vallecular cyst (3.1\%) followed by glottic web with subglottic stenosis $(3.1 \%)$.

5. Other less common causes include subglottic stenosis, upper tracheal web, subglottic hemangioma, foreign body in the glottis, micrognathia, Pierre Robin sequence and benign cystic teratoma of the neck.

\section{Secondary outcomes:}

1. Percentage of children who required surgical intervention was $23.4 \%$.

2. Type of surgery-

Tracheostomy was the most required surgery. The other surgeries done were tracheostomy with open excision, tracheostomy with endoscopic excision, aryepiglottoplasty, endoscopic excision of vallecular cyst, endoscopic dilatation and application of mitomycin c, removal of foreign body, endoscopic excision and epiglottopexy. Multistage surgeries including tracheostomy, endoscopic excision with intraleisional steroid injection, endoscopic dilatation with application of mitomycin c and expansion laryngotracheoplasty were required in two children. ***

3. At three months follow up, half of the children (50\%)were asymptomatic.

\section{INTRODUCTION}

$\mathrm{T}^{\mathrm{h}}$ he term stridor is derived from the latin verb 'stridulus 'which means to make a harsh noise or shrill sound. Stridor is an audible respiratory noise derived from turbulent airflow due to narrowing or obstruction of the upper airway. It is a sign of partial obstruction of the large airways that requires an immediate diagnosis and acute management. Stridor can be classified as inspiratory, expiratory or biphasic. Inspiratory stridor usually indicates a supraglottic pathology. Glottic and subglottic leisions usually produce biphasic stridor ${ }^{1}$.

Stridor may be congenital or acquired. It can be acute, intermittent or chronic. Laryngotracheal inflammation (croup) is the most common cause of acute stridor. Laryngomalacia is the most common cause of chronic stridor. In the infant and newborn, stridor usually indicates a congenital disorder including laryngomalacia, vocal cord paralysis or subglottic stenosis ${ }^{1}$.

Stridor associated with a fever usually signifies an infectious cause, such as bacterial tracheitis or epiglottitis. In toddlers with acute onset of stridor who are afebrile, aspiration of a foreign body must be in the differential diagnosis. In a child who has been intubated for a long period,iatrogenic subglottic stenosis can be considered, eventhough it is rare.

The outcome of stridor would depend on proper and timely interventions.Protocol for the investigation and management of infant stridor are now well defined.The gold standard in the workup of stridor is an upper and lower airway endoscopy under general and local anaesthesia. Although important, pre-endoscopy assessment including history, physical examination and radiological examination, is only a guide to the type and degree of pathology found during endoscopy.

Often, due to improper investigations all stridor get erroneously labelled as laryngomalacia thus delaying intervention when needed. Management of a stridulous child can be either conservative or surgery depending on the cause. It requires a close cooperation and team work between the paediatrician, otolaryngologist and anaesthetist for the management of stridor in infants.

Most of the studies related to causes, management and outcome of stridor are from western countries. From India there are only limited studies. So, we did this study of stridor in infants and newborns in a tertiary care centre. Here we get the privilege to treat a lot of children with breathing difficulty and noisy respiration ${ }^{\wedge}$ who are referred from peripheral hospitals because of unavailability of resources and equipment. 
So, we did this study to describe the common causes, management and short term outcome of stridor in infants and neonates in an Indian scenario.

\section{AIMS AND OBJECTIVES}

AIM:

To study the causes of stridor in infants and describe the management and follow short term outcome of stridor in infants in a tertiary care centre.

\section{OBJECTIVES}

\section{PRIMARY OBJECTIVE:}

To study the common causes of stridor in children from newborn to one year of age.

SECONDARY OBJECTIVES:

To study the need for surgery and the type of surgical intervention needed in the management of stridor in infants. To study the short term outcome of the child at 3 months.

\section{MATERIALS AND METHODS}

\subsection{STUDY SITE}

The study was conducted at the department of ENT \& Laryngology in sree Mookambika institute of medical sciences kulasekaram, Kanyakumari district south India.

STUDY POPULATION

$\mathrm{t}$

All children in the age group less than one year of both sex including neonates presenting with stridor to the ENT department of sree Mookambika institute of medical sciences kulasekaram, Kanyakumari district south India.

\subsection{STUDY DESIGN:}

A prospective descriptive study 


\subsection{SAMPLE SIZE}

Sample size was calculated using the equation:

$$
\mathrm{n}=\mathrm{z}_{\mathrm{a}}^{2} \times \mathrm{p} \times(100-\mathrm{p})
$$

where, $\mathrm{a}=$ Type I error $« 5 \%$

$\mathrm{z}_{\mathrm{a}}=1.96$

$\mathrm{p}=$ expected proportion of variable of interest

$\%$ of infants with laryngomalacia $=60 \%$, obtained from the study - Laryngomalacia:

disease presentation, spectrum, and management by Landry AM et al.

$\mathrm{p}=60 \% \mathrm{~d}=$ allowable error $\ll 10-20 \%$ of $\mathrm{p}=(20 / 1-00) \times 60=12 \mathrm{~d}=12$

$(1.96)^{2} \times 60 \times 40$

Thus, $\mathrm{n}=\quad-\quad=64$

The sample size, $\mathrm{n}=64$

\subsection{STUDY DURATION}

The study was conducted for a period of one and a half years from July 2017 to January 2019.

\subsubsection{History:}

A thorough history taking was done with special emphasis on the age of onset, duration, severity, and progression of the stridor, precipitating events (eg:crying, feeding), effect of positioning (eg: prone, supine, sitting), quality and nature of crying, presence of aphonia. Other associated symptoms include paroxysms of cough, aspiration, difficulty feeding, drooling, sleep disordered breathing, history of colour change, cyanosis, respiratory effort, and apneoa.

Perinatal history regarding maternal condylomata, type of delivery (including shoulder dystocia), endotracheal intubation use and duration, and presence of congenital anomalies was taken.

Past surgical history, particularly neck or cardiothoracic surgeries, any history of NICU stay and history of intubation was asked for to rule out intubation injuries.

A feeding and growth history was evaluated. Any history of regurgitation and spitting up of feed was asked for to rule out gastroesophageal reflux.

\subsubsection{Physical examination:}

On initial presentation, the child was assessed for the type and severity of stridor and respiratory compromise. Special attention is given to the heart rate and respiratory rate, cyanosis, use of accessory muscles of respiration, nasal flaring, level of consciousness and responsiveness. The presence of subcostal, intercostal and suprasternal recession was looked for. A detailed examination of the craniofacial morphology, patency of the nares and cutaneous hemangioma was done. Examination of the oral cavity and oropharynx was done to look for any mass, cleft palate and other congenital malformations.

Further investigations and management were done as per hospital protocol.

\subsubsection{Preendoscopy investigations:} SPECIFIC:

1. Serum calcium

2. Thyroid function test

3. Xray chest and neck

4. VideoFlouroscopy - to assess swallowing in children with feeding difficulties.

5. Echocardiography - to exclude vascular rings or slings.

6. ArterialBlood Gas Analysis (ABG)

7. CT or MRI neck

\subsubsection{Endoscopy:}

ROUTINE: 
Flexible fibre-optic nasopharyngoscopy and laryngoscopy (with patient awake) to detect supraglottic and laryngeal lesions and a few subglottic leisions and observe vocal cord movement.

SPECIFIC:

Laryngotracheobronchoscopy(LTB) under general anaesthesia - using rigid Hopkins rod telescopes.

Once the etiology is established further management can be either conservative or surgical depending on the site and severity of obstruction.

\subsubsection{Management:}

1. CONSERVATIVE MANAGEMENT-

- $\quad$ prone position

- $\quad$ cardiorespiratory and oxygen saturation monitoring

- $\quad$ intravenous fluids if significant respiratory distress or feeding problems (choking/aspiration)

- oxygen therapy

- continuous positive airway pressure, intubation and mechanical ventilation

- $\quad$ pharmacotherapy with intravenous or oral steroids.

\section{SURGICAL MANAGEMENT -}

Surgical management depends on the specific lesion that causes stridor. Indications for surgical correction include the following.

1. Failure to thrive, defined as a weight for age that falls below the $5^{\text {th }}$ percentile on multiple occasions or a weight deceleration that crosses two major percentile lines on a growth chart.

2. Cyanotic spells.

3. Severe respiratory distress.

Surgical procedures which were used to treat stridor in this study include the following:

$*_{-\gg}$

1. Aryepiglottoplasty for laryngomalacia types I and II.

2. Epiglottopexy for laryngomalacia type III.

3. Tracheostomy for bilateral vocal cord motion impairment.

4. Endoscopic dilatation for subglottic stenosis and upper tracheal web.

5. Laryngofissure and expansion laryngotracheoplasty for glottic web and subglottic stenosis.

6. Endoscopic excision of vallecular cyst (coblator assisted).

7. Removal of foreign body under GA.

8. Open excision and tracheostomy for benign cystic teratoma of neck.

, A

\subsubsection{Follow -up:}

A short term follow up of all the children was done at three months. At the follow up visit, children were assessed for the presence of stridor. Flexible laryngoscopy was done in postoperative patients and those with no symptom improvement.

\subsection{OUTCOME VARIABLES: \\ 1. PRIMARY OUTCOME}

Common causes of stridor in infants and neonates.

2. SECONDARY OUTCOMES -

1 .Percentage of infants requiring surgical intervention.

2.Percentage of infants who were symptom free at the end of three months.

\subsection{DATA COLLECTION METHODS:}


A structured proforma containing data regarding essential demographic details, clinical features, investigations, diagnosis, treatment and follow up to measure the outcome of this study was filled by the principal investigator. Data collection form is enclosed with the Annexure 1.

\subsection{STATISTICAL METHODS:}

Statistical analysis was performed using the software SPSS version 17.0. All the categorical variables were expressed in percentages (\%) and frequency (n).

\subsection{ETHICAL CONSIDERATIONS:}

Informed consent was taken from the parents/guardian regarding inclusion in the study.

\section{RESULTS AND ANALYSIS}

\subsection{DEMOGRAPHIC DATA:}

Table 2: Age distribution of the study population

\begin{tabular}{|l|l|l|}
\hline Age & Count & Percent \\
\hline Neonates & 17 & 26.6 \\
\hline Infants & 47 & 73.4 \\
\hline
\end{tabular}

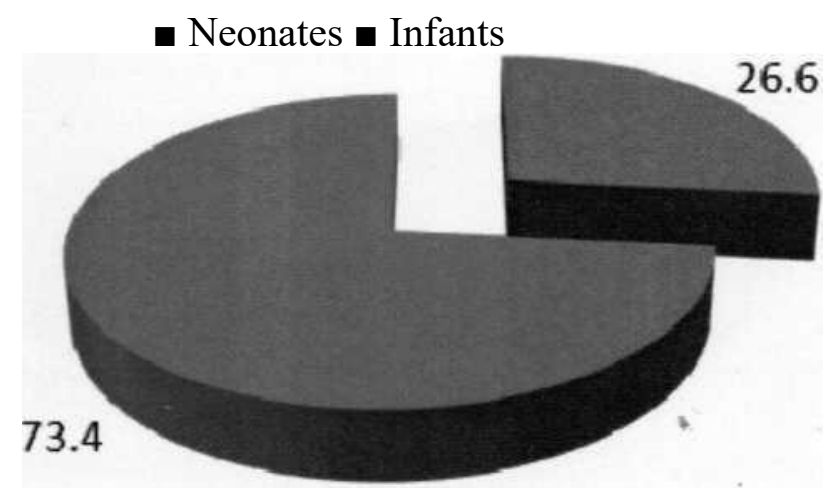

Figure 22: Age distribution of the study population

During the period of study, 64 children presented with stridor. Out of the 64,47 were infants $(73.4 \%)$ and 17 neonates $(26.6 \%)$. 
Table 5: Sex distribution of children with laryngomalacia

\begin{tabular}{|l|l|l|}
\hline Sex & Count & Percent \\
\hline Female & 25 & 56.8 \\
\hline Male & 19 & 43.2 \\
\hline
\end{tabular}

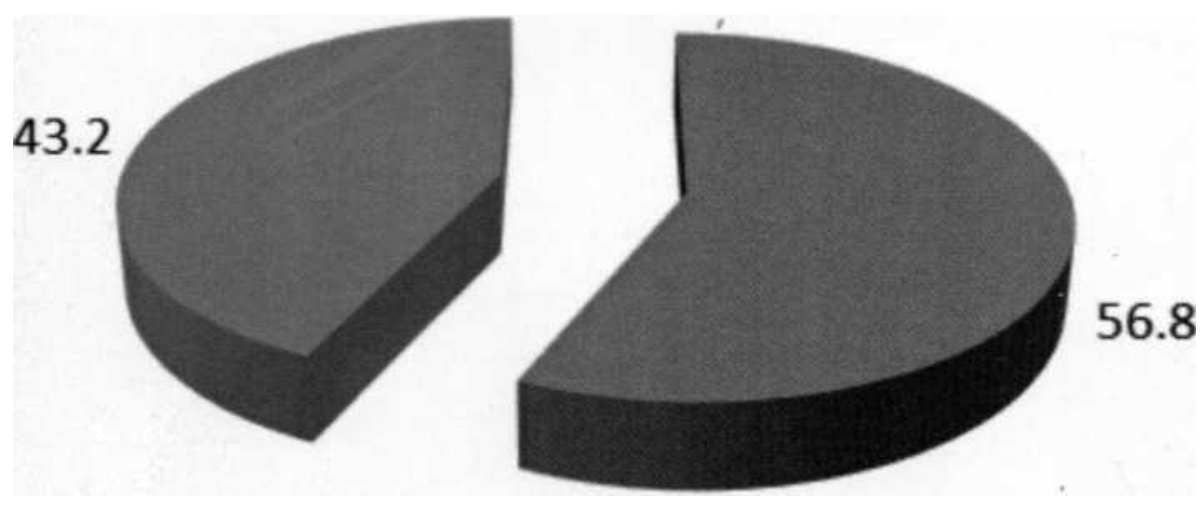

- females a males

Figure 25: Sex distribution of children with laryngomalacia

Among the children with laryngomalcia, $25(56.8 \%)$ were females and $19(43.2 \%)$ babies were males. 
Table7: Distribution of children with laryngomalacia according to term of delivery

\begin{tabular}{|l|l|l|}
\hline Term of delivery & Count & Percent \\
\hline Pre term & 4 & 9.1 \\
\hline Term & 40 & 90.9 \\
\hline
\end{tabular}

9.1

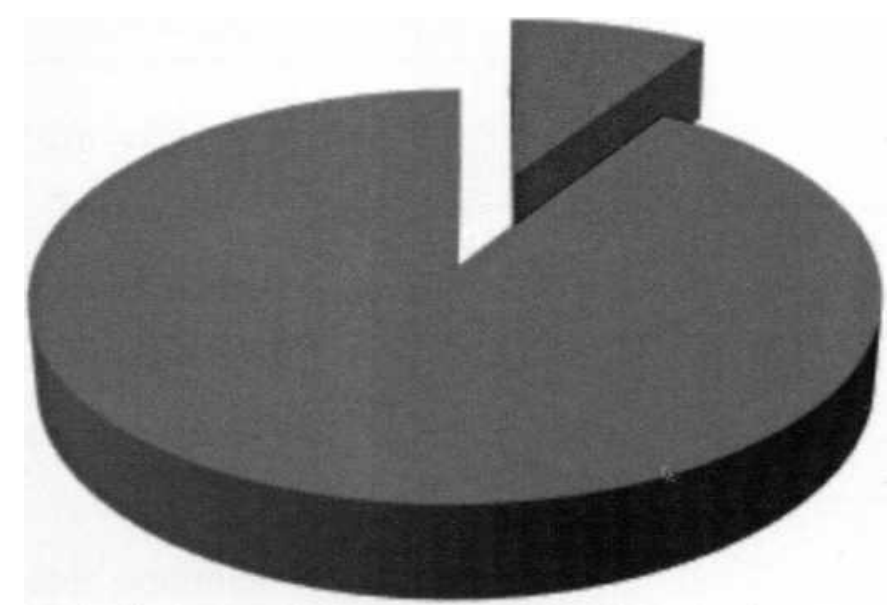

90.9

- Preterm aTerm

Figure 27: Distribution of children with laryngomalacia according to term of delivery Among the babies with laryngomalacia, 40 were term infants $(90.9 \%)$ and 4 were preterm $(9.1 \%)$.

Table 8: Presence of associated congenital anomalies

\begin{tabular}{|l|l|l|}
\hline Associated congenital anomalies & Count & Percent \\
\hline Absent & 48 & 75 \\
\hline Present & 16 & 25 \\
\hline
\end{tabular}

16 children $(25 \%))$ had associated congenital anomalies.

Table 9 : Frequency of congenital anomalies 


\begin{tabular}{|l|l|l|}
\hline Type of congenital anomaly & Count & Percent \\
\hline Hypothyroidism & 4 & 6.3 \\
\hline Congenital heart disease & 6 & 9.4 \\
\hline Neurological abnormalities & 3 & 4.7 \\
\hline Pierre Robin syndrome & 1 & 1.6 \\
\hline Benign cystic teratoma & 1 & 1.6 \\
\hline
\end{tabular}




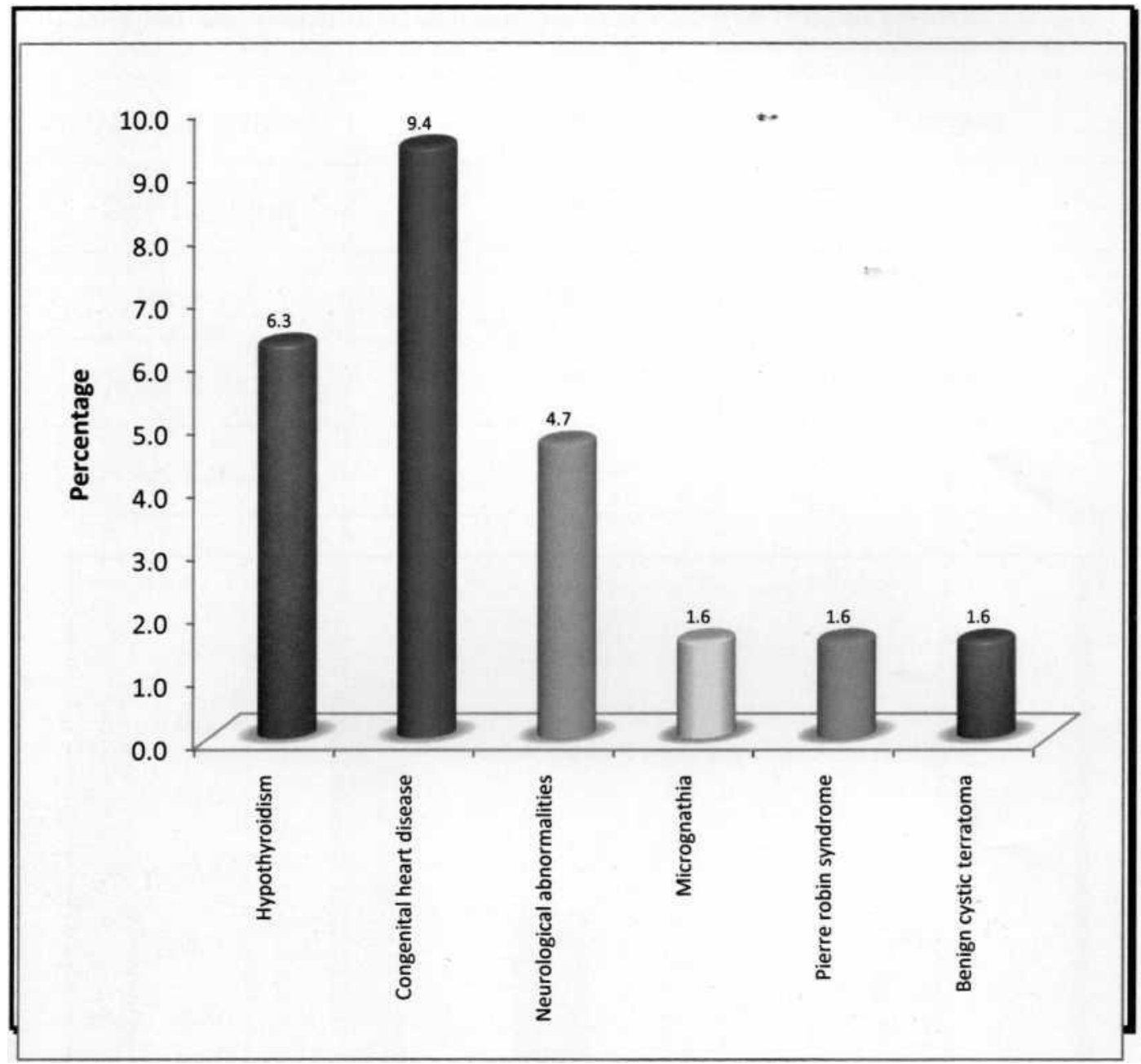

Figure28: Frequency of congenital anomalies

V

Most common anomaly was congenital heart disease $(9.4 \%)$, followed by congenital hypothyroidism $(6.3 \%)$ and developmental delay (4.7\%). One child had Pierre Robin syndrome and one child had benign cystic teratoma of the neck and one child had micrognathia. 
Table 10: Distribution of the sample according to time of onset of stridor

\begin{tabular}{|l|l|l|}
\hline Onset of stridor & Count & \multicolumn{1}{|c|}{ Percent } \\
\hline Day 1 of birth & 26 & 40.6 \\
\hline Days 2-7 & 16 & 25.0 \\
\hline Day 8-1 month & 7 & 10.9 \\
\hline After 1 month & 15 & 23.4 \\
\hline
\end{tabular}

$45.0-$

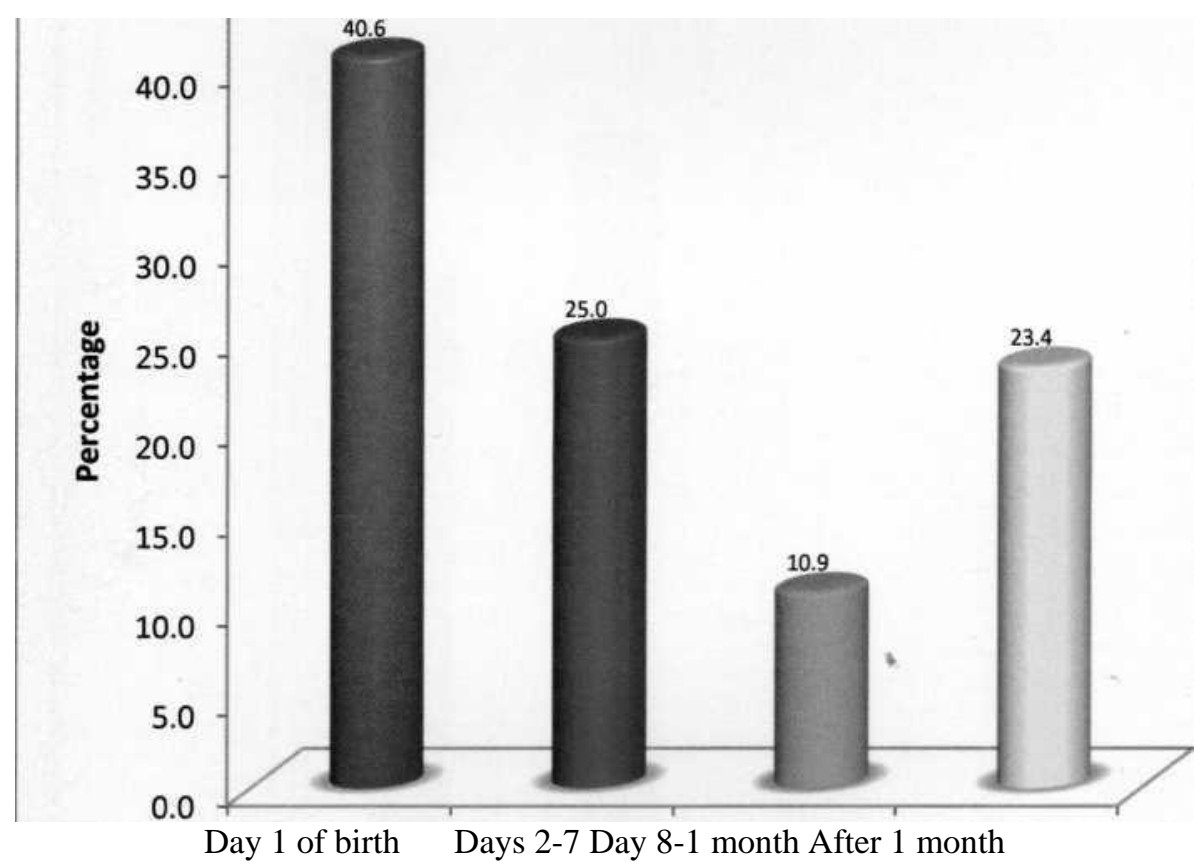

Figure 29: Distribution of the sample according to time of onset of stridor

$40.6 \%$ children had onset of stridor at day one of birth. $25 \%$ babies had onset of stridor in the first week, $10.9 \%$ babies had stridor in the first month. $23.4 \%$ babies developed stridor after one month of birth.

Table 17: Frequency of flexible nasopharyngolaryngoscopy findings

\begin{tabular}{|l|l|l|}
\hline Flexible nasopharyngolaryngoscopy & Count & Percent \\
\hline Normal study & 3 & 4.7
\end{tabular}




\begin{tabular}{|l|l|l|}
\hline Laryngomalacia & 44 & 68.8 \\
\hline Laryngomalacia typel & 20 & 31.3 \\
\hline Laryngomalacia typell & 10 & 15.6 \\
\hline Laryngomalacia typelll & 7 & 10.9 \\
\hline Laryngomalacia type I + II & 7 & 10.9 \\
\hline Vallecular cyst + laryngomalacia type III & 1 & 1.6 \\
\hline Bilateral vocal cord motion impairment & 8 & 12.5 \\
\hline Bilateral vocal cord palsy & 7 & 10.9 \\
\hline Bilateral vocal cord paresis & 1 & 1.6 \\
\hline Vallecular cyst & 2 & 3.1 \\
\hline Upper tracheal web & 1 & 1.6 \\
\hline Subglottic stenosis & 1 & 1.6 \\
\hline Foreign body glottis & 1.6 \\
\hline Subglottic hemangioma & 1.6 \\
\hline Laryngeal web & 1.6 & 3.6 \\
\hline
\end{tabular}




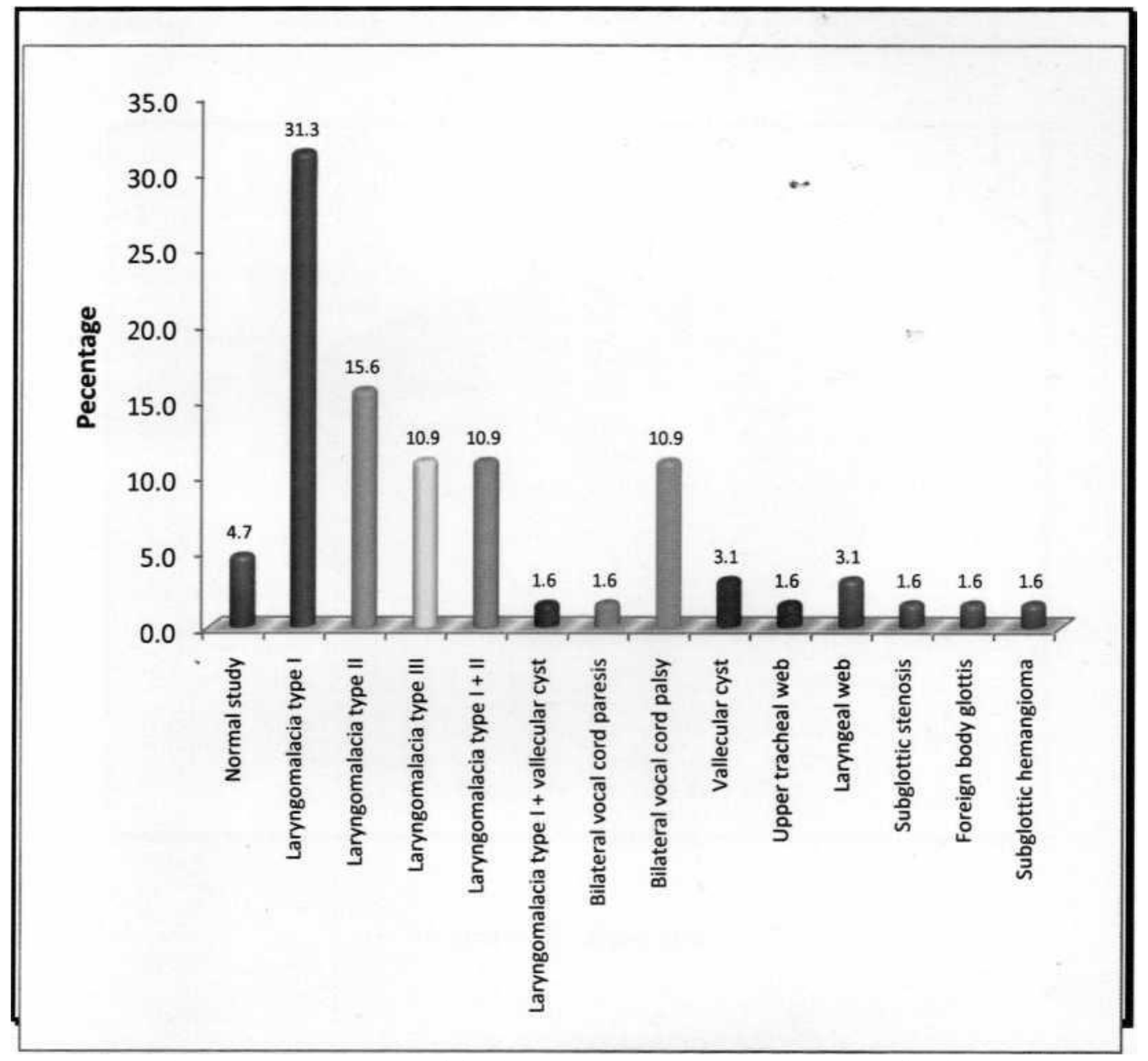

Figure 36: Frequency of flexible nasopharyngolaryngoscopy findings

Flexible nasopharyngolaryngoscopy showed a normal study in 3 children (4.7\%). Laryngomalacia was the most common finding in 44 cases $(68.8 \%$ ), type I in $31.3 \%$ cases, type II in $15.6 \%$, type III in $10.9 \%$ and combination of types I and II in $10.9 \%$ cases. Bilateral vocal cord palsy was seen in 7 children $(10.9 \%)$, bilateral vocal cord paresis was seen in 1 child (1.6\%). Vallecular cyst was the finding in 2 cases $(3.1 \%)$, one child had a vallecular cyst with associated type III laryngomalcia. Glottic web was seen in 2 cases (3.1\%). Subglottic stenosis was seen in one case (1.6\%). Upper tracheal web was seen in one case (1.6\%). Subglottic hemangioma was seen in one case (1.6\%). Foreign body in the glottis was seen in one child (1.6\%). 
Table 18: Frequency of the causes of stridor

\begin{tabular}{|l|l|l|}
\hline Diagnosis & Count & Percent \\
\hline Laryngomalacia & 44 & 68.8 \\
\hline Laryngomalacia typel & 20 & 31.3 \\
\hline Laryngomalacia typell & 10 & 15.6 \\
\hline Laryngomalacia typelll & 7 & 10.9 \\
\hline Laryngomalacia type I + II & 7 & 10.9 \\
\hline Vallecular cyst + laryngomalacia type III & 1 & 1.6 \\
\hline Bilaeral vocal cord motion impairment & 8 & 12.5 \\
\hline Bilateral vocal cord palsy & 7 & 10.9 \\
\hline Bilateral vocal cord paresis & 1 & 1.6 \\
\hline Vallecular cyst & 2 & 3.1 \\
\hline Upper tracheal web & 1 & 1.6 \\
\hline Subglottic stenosis & 1 & 1.6 \\
\hline Foreign body glottis & 1 & 1.6 \\
\hline Subglottic hemangioma & 1 & 1.6 \\
\hline Glottic web with subglottic stenosis & 2 & 3.1 \\
\hline Micrognathia & 1 & 1.6 \\
\hline Pierre robin syndrome & 1 & 1.6 \\
\hline Benign cystic teratoma of neck & 1 & 1.6 \\
\hline & & \\
\hline
\end{tabular}

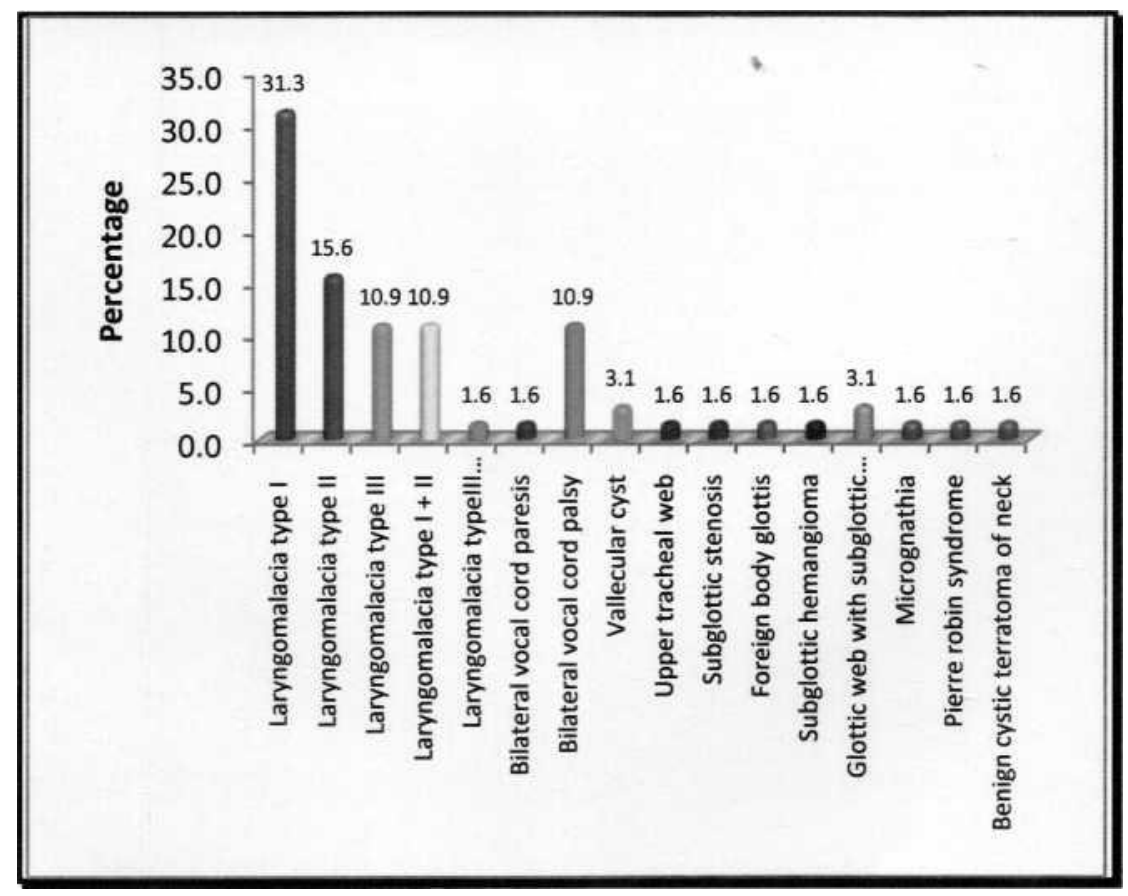

Figure 38: Frequency of the causes of stridor 


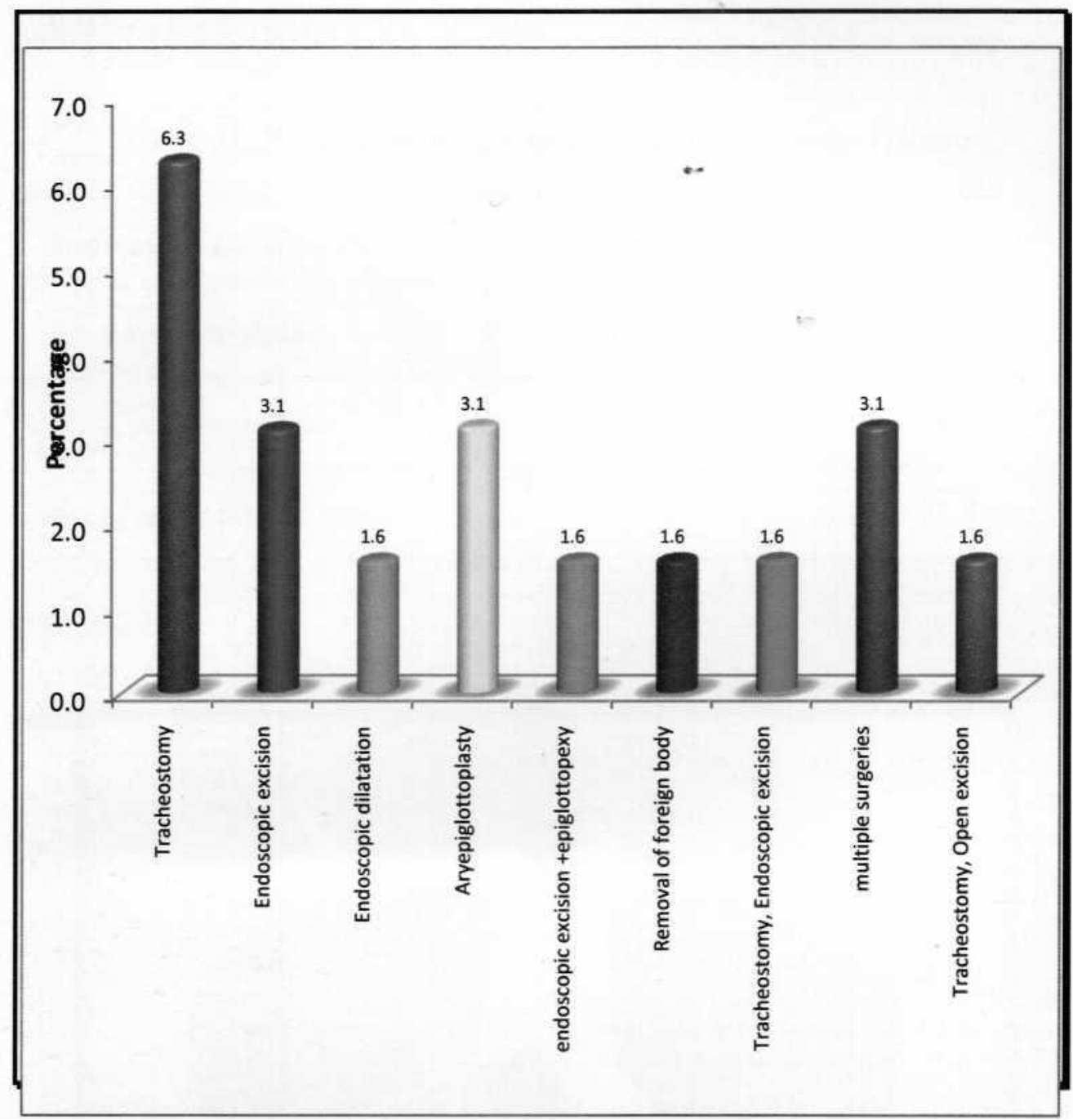

Figure 40: Frequency of surgeries required

The most common surgery was tracheostomy, done in $4(6.3 \%)$ children. Endoscopic excision was done in $2(3.1 \%)$ children. Aryepiglottoplasty was done in 2children (3.1\%). Endoscopic excision with epiglottopexy was needed in one child (1.6\%). Tracheostomy with endoscopic dilatation was needed in one case. Tracheostomy with endoscopic excision was done in one child (1.6\%). Tracheostomy with open excision was needed in one case (1.6\%). Removal of foreign body from the glottis was needed in one child (1.6\%). Multiple surgeries were required in 2 children $(3.1 \%)$, one with laryngeal web and another child with subglottic stenosis. 
5.7 OUTCOME AT 3 MONTHS:

Table 22: Distribution of study population according to outcome at 3 months

\begin{tabular}{|l|l|l|}
\hline Outcome at 3 months & Count & Percent \\
\hline No stridor & 32 & 50.0 \\
\hline Has stridor, but better than before & 12 & 18.8 \\
\hline Has stridor, no relief & 11 & 17.2 \\
\hline On tracheostomy & 6 & 9.4 \\
\hline Lost follow up & 3 & 4.7 \\
\hline
\end{tabular}

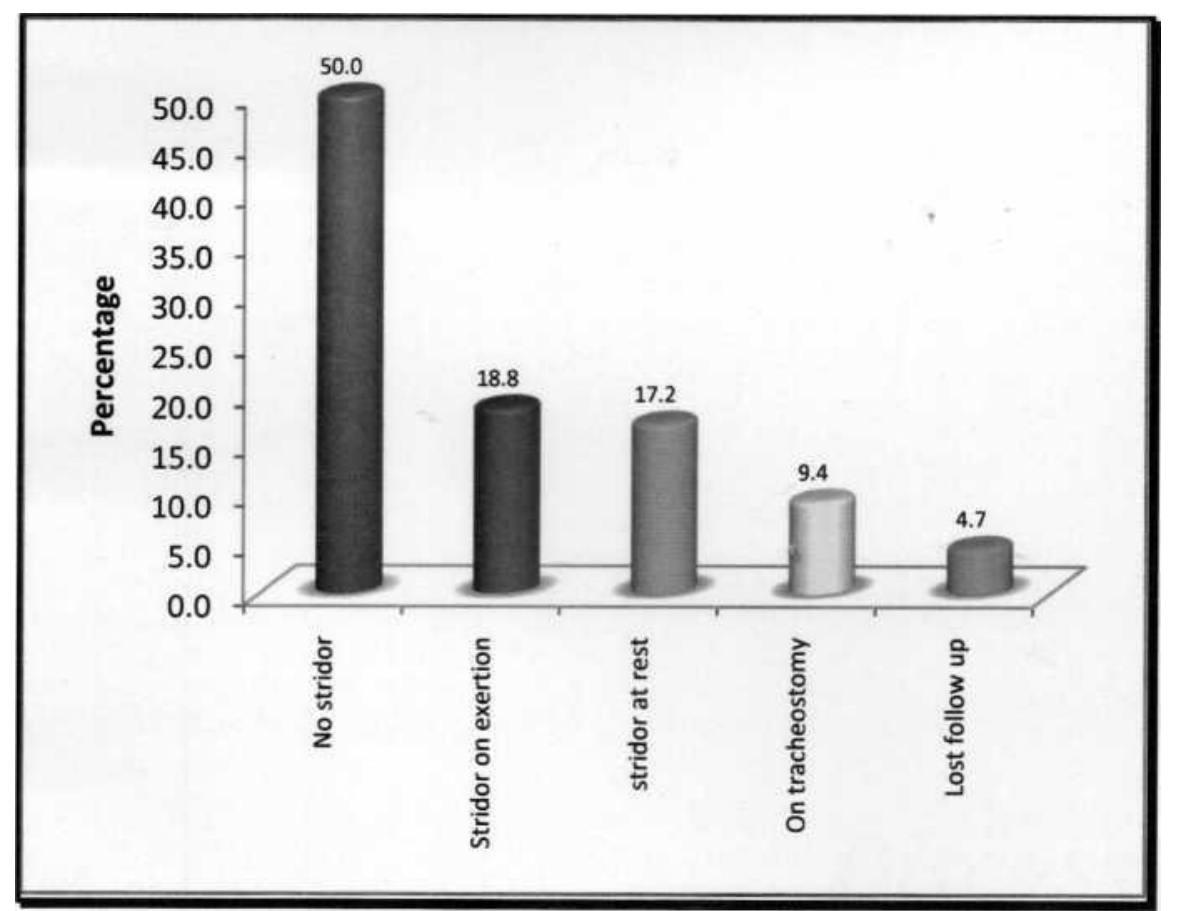

Figure 42: Distribution of the study population according to outcome at 3 months

32 children $(50 \%)$ had no stridor at three months. 12 children $(18.8 \%)$ had stridor on exertion. 11 children $(17.2 \%)$ had stridor at rest. 6 children $(9.4 \%)$ were on tracheostomy and 3 children $(4.7 \%)$ were lost to follow up. 


\section{DISCUSSION}

This was a prospective descriptive study conducted at a tertiary care centre in Trivandrum. During the study period of one and a half years, 64 children under one year of age who presented to ENT OP and also referred from Pediatrics and Neonatology departments with the complaint of stridor were included in the study.

\subsection{Demography:}

Of the 64 children in the study population, 17 (26.6\%)were neonates and $47(73.4 \%)$ were infants, with 35 females (54.7\%) and 29 males (45.3\%).There were 44 children with laryngomalacia, of which $11(25 \%)$ were neonates and 33(75\%) were infants. Of them, 25 children (56.8\%)were females and $19(43.2 \%)$ were males. Females outnumbered males in this study, which is in variance with the study done by Zoumalan et al ${ }^{65}$, where $59 \%$ were boys and $41 \%$ were girls.

\subsection{History:}

Majority of the children were term infants (84.4\%). Only $15.6 \%$ were preterm. Among the children with laryngomalacia, term babies were $90.9 \%$, while preterm babies were only $9.1 \%$. This is in accordance with the study by Landry AM et al ${ }^{11}$, which states that congenital stridor is more common in term children than in preterm children.

16 children $(25 \%)$ had associated congenital anomalies. The most common associated anomaly was congenital heart disease $(9.4 \%)$ followed by congenital hypothyroidism in $6.3 \%$ and neurological abnormalities in $4.7 \%$.

The peak time of onset of stridor was on the first day of birth (40.6\%).25\% children developed stridor in the first week, 23.4\%developed stridor between eight days to one month. 10.9\% children developed stridor after 1 month. Among the children diagnosed with laryngomalacia, the peak period of onset of stridor was in the first week of birth seen in $36.4 \%$ children closely followed by $29.5 \%$ on the first day of birth. $18.2 \%$ children developed stridor after one month and $15.9 \%$ had onset of stridor between 8 days to one month of birth.

10 children $(15.6 \%)$ had history of failure to thrive, $6(9.4 \%)$ children had history of cyanotic spells. These were important indicators for the choice of management, whether conservative or surgical. Feeding difficulty was present in $40.6 \%$ children.

\subsection{Physical examination:}

Stridor was inspiratory in 60 children $(93.8 \%)$ which suggests supraglottic causes were more common than glottic and subglottic causes. $78.1 \%$ children had a normal cry. Cry was weak in $20.3 \%$ and absent in 1 child (1.6\%). Chest retractions were present in $60.9 \%$ children.

\subsection{Investigations:}

Flexible nasopharyngolaryngoscopy is the gold standard investigation for children with stridor. It was done in all 64 children, either in the $\mathrm{OP}$ or on the bedside for babies who were in-patient. Findings were recorded. The most common finding was laryngomalacia seen in 44 children (68.8\%) followed by bilateral vocal cord motion impairment in 8 children (12.5\%). This is in par with the study done by Botma $\mathrm{M}$ et at ${ }^{9}$ to know the use of flexible fibreoptic laryngoscope in infants with The most common cause of stridor was laryngomalcia, seen in 44 cases (70.3\%), followed by bilateral vocal cord motion impairment seen in 8 children (12.5\%), vallecular cyst seen in 2 children (3.1\%), congenital glottis web with subglottic stenosis seen in 2 children $(3.1 \%)$. There was one case (1.6\%) of vallecular cyst with type III laryngomalacia. The other causes were subglottic stenosis (1.6\%), upper trachea] web (1.6\%), subglottic hemangioma (1.6\%), foreign body in the glottis (1.6\%), micrognathia (1.6\%), Pierre Robin syndrome (1.6\%), benign cystic teratoma of the neck $(1.6 \%)$. This in contrast to the Indian study done by Rajan Joshi et a $/{ }^{81}$ where the most common cause was laryngomalacia $(40 \%)$, followed by subglottic stenosis (28\%), bilateral vocal cord palsy (15.6\%), laryngeal web(12.5\%) and interarytenoid cleft (3.1\%).

\subsection{Management:}

\subsubsection{Conservative Management:}

Out of the 64 children, 49 were managed conservatively (76.6\%). Conservative management included proper positioning of the child, oxygen or CPAP, mechanical ventilation, intravenous fluids, intravenous or oral steroids, nebulisation with budesonide or adrenaline, proton pump inhibitors. Among the 44 children with laryngomalacia. 42 children (95.5\%)were managed conservatively with reassurance of the parents, education to look for warning signs in the baby and regular follow up at 3 months interval. Of these 42 children ,3 had history of failure to thrive, one child with type III, one with type II and one child with combination of type I and II laryngomalcia, one child with type I laryngomalcia had history of cyanotic spells. Although these were indications for surgical intervention, these children were

managed conservatively as their parents were not willing to give consent for any surgery.

Of the 7 children with bilateral vocal cord abductor palsy, 3 children were managed conservatively with regular follow-up whose parents were not willing to give consent for surgery. One child with bilateral abductor paresis was also managed conservatively. The child with subglottic hemangioma was managed with oral propranolol at $2 \mathrm{mg} / \mathrm{kg}$ day in three divided doses, gradually and stopped over 6 months. There was one child with micrognathia, who had only mild stridor and there was no indication for surgical intervention. The child was discharged after reassuring the parents and advised follow up at 3 months. One child who presented with the classical features of Robin sequence, u-shaped cleft palate, retrognathia and glossoptosis, did not require any active intervention as the stridor was only mild. There was no history of failure to thrive or cyanotic spells. Repair of cleft palate was advised by the pediatric surgeon after 10 months of age. The child was discharged with advice regarding prone positioning, warning signs and follow up after 3 months.

\subsubsection{Surgical management:}


All the surgeries were under general anaesthesia. Difficulty in intubation was anticipated in all of these cases. When intubation was not possible, apnoeic ventilation was used.

The most needed surgery was tracheostomy. Tracheostomy alone was needed in 4 children (6.3\%) with bilateral vocal cord abductor palsy who presented with severe respiratory distress. Two children diagnosed with vallecular cyst were treated

with endoscopic excision with coblator. One child who had vallecular cyst with associated type III laryngomalcia had failure to thrive and severe respiratory distress. She was treated with endoscopic coblator assisted excision of the cyst and epiglottopexy.

For two children with combination of laryngomalcia types I and II, the indication for surgery was failure to thrive. They were treated with endoscopic aryepiglottoplasty with microscissors.

There was a child who presented with sudden onset respiratory distress and stridor, started following a feed. Flexible nasopharyngolaryngoscopy showed foreign body in the glottis. The child was immediately taken to the operation theatre and the foreign body, which was a plastic cover was removed under general anaesthesia.

One child who presented with stridor and severe respiratory distress with a history of prolonged intubation for seizures few months back. Laryngotracheobronchoscopy under anaesthesia showed a concentric web in the upper trachea $1 \mathrm{~cm}$ below the glottis. The child was managed with endoscopic dilatation and local application of mitomycin c. He was extubated on postoperative day 2 and discharged when he started taking oral feeds normally on second postoperative day.

One newborn baby who was referred with a large swelling on the right side of neck since birth. There was a gradually progressing stridor and cyanotic spells. MRI of the neck was suspicious of soft tissue tumour. Open excision of the mass and tracheostomy was done. Postoperative child was kept on ventilator support for 48 hours. Oral feeding was started on the third postoperative day. The child was decannulated on the $15^{\text {th }}$ postoperative day.

An infant presented with biphasic stridor and respiratory distress, with no past history of intubation. Flexible nasopharyngolaryngoscopy was suggestive of subglottic stenosis. Laryngotracheobronchoscopy under anaesthesia showed soft subglottic stenosis grade 3 according to Myer-Cotton staging. Tracheostomy was done. Endoscopic dilatation with intraleisional steroid injection was done twice at 1 month interval. There was difficulty in decannulation. Hence, laryngofissure and expansion laryngotracheoplasty with anterior costal cartilage graft was done after 2 months.

Another newborn child who was referred with history stridor and breathing difficulty since birth, on flexible nasopharyngolaryngoscopy showed glottic web involving anterior two-thirds of vocal cords. Laryngotracheobronchoscopy showed thick anterior glottis web with Myer-Cotton staging grade 3 hard subglottic stenosis. Tracheostomy was done. Child was then treated with endoscopic excision of the web with diode laser and expansion laryngotracheoplasty with anterior costal cartilage graft after one month. There was difficulty in decannulating the baby. The child needed endoscopic dilatation with intraleisional steroid injection twice after the surgery at six weeks interval.

Another newborn baby diagnosed with glottic web on flexible nasopharyngolaryngoscopy was subjected to laryngotracheobronchoscopy under general anaesthesia. Glottic web grade 3 according to Cohen's classification was seen involving the entire length of membraneous vocal cords extending into the anterior subglottis. Web was excised with diode laser and tracheostomy was done. On the $7^{\text {th }}$ postoperative day the child was discharged with plan for laryngotracheoplasty at a later date.

6.6 Indication for surgery:

15 children (23.4\%) needed surgery. The main indicators for surgery were failure to thrive in 7 children (43.8\%), severe respiratory distress in 6 children (37.5\%) followed by cyanotic spells in 3 children (18.8\%).

\subsection{Follow -up:}

All 64 children were advised regular follow up. Among the children who were managed conservatively, 48 were advised follow up at 3 months interval. The child with subglottic hemangioma was followed up at 2 weeks interval for modification of the dose of oral propranolol. All postoperative cases were advised first follow up at 2 weeks, then at 6 weeks and then at 3 months. For the purpose of this study, the follow up of all children at 3 months of presentation to our department was documented.

$¥$

On follow up at 3 months, 32 children (50\%) had no stridor. 12 children (18.8\%) had stridor on exertion. 11 children (17.2\%) had stridor at rest. 6 children (9.4\%) were on tracheostomy, 3 of them were cases of bilateral abductor palsy and one child was a case of glottic web. We lost follow up of three children $(4.7 \%)$.

Of the 49 children who were managed conservatively, 24 (49\%)children were symptom free at 3months.This included 10 children with type I laryngomalacia, 6 children with type II laryngomalacia, 4 children with type III laryngomalacia, 2 children with combined laryngomalacia types I and II, 1 child with micrognathia, 1 child with bilateral vocal cord abductor palsy.

$12(24.5 \%)$ children had stridor on exertion. This included 5 children with laryngomalacia type I, 3 children with laryngomalacia type II, 1 child with type III laryngomalacia, 1 child with laryngomalacia combined types I and II, 1 child with subglottic hemangioma and 1 child with bilateral vocal cord abductor palsy.

$10(20.4 \%)$ children had stridor at rest, which included 4 children with type I laryngomalacia, 1 child with type II laryngomalacia, 2 children with type III laryngomalacia, 2 children with laryngomalacia combined types I and II. 1 child with Robin sequence, 1 child with bilateral vocal cord abductor paresis.

One child (2\%) with type I laryngomalacia was lost to follow up.

Of the 15 children who were managed with surgery, 8 (53.3\%) children were asymptomatic at 3 months followup. This included 2 children who underwent aryepiglottoplasty, 2 children who underwent endoscopic excision, 1 child who underwent foreign body 
removal, 1 child who underwent open excision with tracheostomy, 1 child who was treated with endoscopic dilatation and application of mitomycin c and 1 child who underwent endoscopic excision of vallecular cyst and epiglottopexy.

$6(40 \%)$ children were still on tracheostomy at 3 months. This included 3 children with bilateral vocal cord abductor palsy, 2 children who underwent expansion laryngotracheoplasty and 1 child with laryngeal web who underwent endoscopic excision and tracheostomy. One child $(6.7 \%)$ who was a case of bilateral vocal cord abductor palsy was lost to follow up.

\section{SUMMARY AND CONCLUSIONS}

\subsection{Summary:}

During this one year prospective descriptive study, 64 children under one year age presented to the study centre with complaints of stridor. There were 17 neonates and 47 infants, 35 females and 29 males, 54 term and 10 preterm babies. 16 children had other associated congenital anomalies, congenital heart disease being the most common anomaly.

The peak period of onset of stridor was on the first day of birth in $40.6 \%$ children. Stridor was inspiratory in 60 children (93.8\%) and biphasic in $4(6.3 \%)$. Chest retractions were present in 39 children $60.9 \%)$ and 26 babies $(40.6 \%)$ had feeding difficulties.

The cause of stridor in infants in this study was congenital in $96.9 \%$ cases and acquired in $3.1 \%$ cases. The most common cause of stridor was laryngomalcia, seen in 44 cases $(70.3 \%)$, followed by bilateral vocal cord motion impairment seen in 8 children (12.5\%), vallecular cyst seen in 2 children (3.1\%), laryngeal web seen in 2 children (3.1\%). There was one child (1.6\%) with a vallecular cyst with associated laryngomalacia type III. The other causes were subglottic stenosis (1.6\%), upper tracheal web (1.6\%), subglottic hemangioma (1.6\%), foreign body in the glottis (1.6\%), micrognathia (1.6\%), Pierre Robin syndrome (1.6\%), benign cystic teratoma of the neck $(1.6 \%)$.

Laryngomalacia was the most common cause of stridor in children under one year of age. It was more common in infants (75\%) than in neonates $(25 \%)$, in females $(56.8 \%)$ more than males $(43.2 \%)$ and in term babies (90.9\%) than in preterm babies $(9.1 \%)$. The peak period of onset of stridor was in the first week of birth (36.4\%). Type I laryngomalacia was the most common, seen in 20 children (31.3\%), followed by type II in 10 children (15.6\%), type III in 7 children (10.9\%) and combination of types I and II were seen in 7 children $(10.9 \%)$.

$49(76.6 \%)$ children were managed conservatively with prone positioning, nebulisation, proton pump inhibitors and regular follow up. 15 children (23.4\%) underwent surgery. The main indications for surgery were failure to thrive in 7 children (43.8\%), followed by severe respiratory distress in 6 children (37.5\%) and cyanotic spells in 3 children (18.8

The most done surgery was tracheostomy. Tracheostomy alone was done in $6.3 \%$ children. Tracheostomy with open excision was needed in one child (1.6\%). Tracheostomy with endoscopic excision was done in one child (1.6\%). Aryepiglottoplasty was done in $3.1 \%$ children. Endoscopic excision was done in $3.1 \%$ children. The other surgeries required include endoscopic dilatation and application of mitomycin c (1.6\%), removal of foreign body (1.6\%), endoscopic excision and epiglottopexy (1.6\%). Multiple surgeries in different stages were required in two children $(3.1 \%)$.

At three months follow up, 32 children (50\%) had no stridor. 12 children (18.8\%) had stridor on exertion. 11 children (17.2\%) had stridor at rest. 6 children (9.4\%) were on tracheostomy and 3 children $(4.7 \%)$ were lost to follow up.

\subsection{Conclusions:}

The following conclusions were made from this prospective descriptive study:

\section{Primary outcome - Common causes of stridor in infants}

6. Congenital causes were more common than acquired causes.

7. Laryngomalcia was the most common cause of stridor (68.8\%) in infants presented our centre. Type I was the most common subtype followed by type II, followed by type III and combination of types I and II.

8. The second common cause was bilateral vocal cord motion impairment (12.5\%).

9. The third common cause was vallecular cyst (3.1\%) followed by glottic web with subglottic stenosis (3.1\%).

10. Other less common causes include subglottic stenosis, upper tracheal web, subglottic hemangioma, foreign body in the glottis, micrognathia, Pierre Robin sequence and benign cystic teratoma of the neck.

\section{Secondary outcomes:}

4. Percentage of children who required surgical intervention was $23.4 \%$.

5. Type of surgery-

Tracheostomy was the most required surgery. The other surgeries done were tracheostomy with open excision, tracheostomy with endoscopic excision, aryepiglottoplasty, endoscopic excision of vallecular cyst, endoscopic dilatation and application of mitomycin c, removal of foreign body, endoscopic excision and epiglottopexy. Multistage surgeries including tracheostomy, endoscopic excision with intraleisional steroid injection, endoscopic dilatation with application of mitomycin c

and expansion laryngotracheoplasty were required in two children.

$*_{\bullet} *$

6. At three months follow up, half of the children (50\%)were asymptomatic.

Though not the main objective of this study, the following observations were also made: 
1. Laryngomalacia was more common in term infants, more in females than in males.

2. The peak period of onset of stridor in laryngomalacia was in the first week of birth.

3. Majority of the children with laryngomalcia could be managed conservatively. Only few required surgery.

4. The main indication for surgery in laryngomalacia was failure to thrive.

\section{REFERENCES}

[1] Simon NP. Evaluation and management of stridor in the newborn. Clinical pediatrics. 1991 April 1:30(4):211-6.

[2] Gilbert EG, Russell KE, Deskin RW. Stridor in the Infant and Child: Assessment, Treatment. AORN Journal. 1993 Jul 31;58(1):21-52.

[3] Clough J. manangement stridor in children. The Practitioner 1995 Dec; $2391557: 724$.

[4] Lees DB. Larynx from an infant with a peculiar form of obstructed respiration Trans PatholSocLond. 1883;34:19.

[5] Cotton RT, Reilly JS. Stridor and airway obstruction. Pediatric Otolaryngology. 1983;2: 1190-204 .

[6] Richter GT, Thompson DM. The surgical management of laryngomalacia Otolaryngol Clin North Am. 2008 Oct 31;41(5):837-64.

[7] Koempel JA, Cotton RT. History of pediatric laryngotracheal reconstruction. Otolaryngol Clin North Am. 2008 Oct 31:41(5):825-34

[8] Mellwain JC. A historical overview of the etiology and treatment of laryngeal stenosis. Arch Otorhinolaryngol. 1989 Oct 1:246(5):336-40.

[9] Cotton RT. Seid AB Management of the extubation problem in the premature child anterior cricoid split as an alternative to tracheotomy Ann Otol Rhinol Laryngol. 1980 Nov 1:89-508-11.

[10] Myer CM OConnor DM, Conn RT Proosed grading system for subglottic stenoisis based on endotracheal tube is Ann Otol Rhino Layngol. 1994 Apr 1;103;31923.

[11] Nicollas R. Trigia JM. The anterior laryngeal webs Otolaryngeal Chis North I 2008 (5) 877-88

[12] O-Lee TJ, Messner A. Subglottic hemangioma. Otolaryngol Clin North Am. 2008 Oct 3141(5):903-11.

[13] McNiece WL. Dierdorf SF. The pediatric airway Semin Pediatr Surg 2004:13:152-165.

[14] Wheeler DS, Spaeth JP, Mehta R, Hariprakash SP, Cox PN. Assessment and management or the pediatric airway. In:Wheeler DS, Wong HR, Shanley TP (eds.) Resuscitation and Stabilization of the Critically Ill Child. London: Springer; 2009, p. 37-40.

[15] Morton, I. N. Large airway obstruction in children Part 1: Causes and Assessment. Royal College of Anaesthetists Newsletter 47.1999:159-162.

[16] Leung AK, Cho H. Diagnosis of stridor in children Am Fam Physician. 1999 Nov:60(8):2289-96.

[17] Landry AM, Thompson DM. Laryngomalacia: disease presentation, spectrum, and management. Int J Pediatr.2012 Feb 27:2012.

[18] Thompson DM. Abnormal sensorimotor integrative function of the larynx in congenital laryngomalacia: a new theory of etiology. The Laryngoscope. 2007 Jun 1;117(S114):1-33.

[19] Dickson JM, Richter GT, Meinzen-Derr J. Rutter MJ, Thompson DM. Secondary airway lesions in infants with laryngomalacia. Ann Otol Rhinol Laryngol 2009;118(1):37-43

[20] Olney DR,, Greinwald JH, Smith RJ, Bauman NM. Laryngomalacia and its treatment. The Laryngoscope. 1999 Nov 1:109(11):1770-5.

[21] Richter GT, Thompson DM. The surgical management of laryngomalacia Otolaryngol Clin North Am. 2008 Oct 31:41(5):837-64.

[22] Holinger LD, Konior RJ. Surgical management of severe laryngomalacia. The Laryngoscope. 1989 Feb 1;99(2):136-42.

[23] Seid AB, Park SM, Keam MJ, Guggenheim S. Laser division of the aryepiglottic folds for severe laryngomalacia. Int J Pediatr Otorhinolaryngol. 1985 Nov 30;10(2):153-8.

[24] King EF, Blumin JH. Vocal cord paralysis in children. Curr Opin Otolaryngol Head Neck Surg. 2009 Dec 1;17(6):483-7.

[25] Miller RH, Duplechain JK Hoarseness and vocal cord paralysis. Head and Neck Surgery-Otolaryngology.1993;1:620-9.

[26] Berke GS. Voice disorders and phonosurgery. Head and Neck Surgery Otolaryngology. 1993;1:644-57.

\section{AUTHORS}

First Author - Dr. Adhavan.E, Junior Resident Department of Otorhinolaryngology, SreeMookambika Institute of Medical Sciences, Kulasekharam, Tamilnadu

Second Author - Dr.Kiren.T, Assistant Professor Department of Otorhinolaryngology, SreeMookambika Institute of Medical Sciences, Kulasekharam, Tamilnadu

Third Author - Dr.Gopakumar K.P, Professor and Head of the Department of Otorhinolaryngology, SreeMookambika Institute of Medical Sciences, Kulasekharam, Tamilnadu

Fourth Author - Dr.Chethan Kumar.G, Associate Professor Department of Otorhinolaryngology, SreeMookambika Institute of Medical Sciences, Kulasekharam, Tamilnadu

Corresponding Author: Dr Adhavan .E ,Junior Resident, Department of Otorhinolaryngology, SreeMookambika Institute of Medical Sciences,Kulasekharam, Tamilnadu, Gmail id:addyuths@gmail.com, Mobile number: 9566270022 
International Journal of Scientific and Research Publications, Volume 7, Issue 8, August 2017

ISSN 2250-3153

www.ijsrp.org 